\title{
Microalgae (Scenedesmus obliquus) dewatering using forward osmosis membrane: Influence of draw solution chemistry
}

\author{
Mathieu Larronde-Larretche, Xue Jin * \\ School of Engineering, University of Glasgow, Scotland G12 8LT, United Kingdom
}

\section{A R T I C L E I N F O}

\section{Article history:}

Received 9 October 2015

Received in revised form 8 December 2015

Accepted 22 January 2016

Available online $\mathrm{xxxx}$

\section{Keywords:}

Forward osmosis

Microalgae dewatering

Reverse solute diffusion

Membrane fouling

Biomass deposition

\begin{abstract}
A B S T R A C T
Forward osmosis (FO) is gaining increasing interests for its potential applications in biofuel generation. In this study, bench-scale experiments were conducted to investigate the FO performance for microalgae dewatering which is one of the technical challenges in algal biofuel production. The filtration performance was assessed by analyzing permeate water flux and algal biomass concentration in the feed solution. Compared to the active layer facing draw solution (AL-DS) orientation ( $>45 \%$ flux reduction), active layer facing feed solution (AL-FS) was more efficient ( $<15 \%$ flux reduction) due to the lower membrane fouling and higher cleaning efficiency (>90\% water flux recovery after deionized water flushing). In the AL-FS orientation, FO performance strongly depended on the draw solution chemistry with $\mathrm{NaCl}$ exhibiting the best results. When $\mathrm{Ca}^{2+}$-containing solution was used as draw solution, microalgae responded to the back diffusion of calcium ions by an extensive excretion of carbohydrates, accelerating the formation of algal flocs, thus enhancing the rate and extent of flux decline and reducing the algae dewatering efficiency. However, most of the flux decline was reversible by simple hydraulic flushing without any chemical cleaning reagents and air scouring. In addition, substantial adsorption of algal biomass was observed on feed spacer. This study has the implication for Scenedesmus obliquus dewatering using FO technology. Selection of AL-FS orientation, $\mathrm{Ca}^{2+}$-free draw solutions and prevention of microalgae adhesion onto feed spacer may significantly improve the efficiency and productivity of the dewatering process.
\end{abstract}

(C) 2016 The Authors. Published by Elsevier B.V. This is an open access article under the CC BY-NC-ND license

(http://creativecommons.org/licenses/by-nc-nd/4.0/).

\section{Introduction}

Microalgae have attracted increasing attention due to their promising application in sustainable biofuel generation, wastewater remediation, carbon dioxide sequestration and pharmaceuticals production [1]. Despite the promise, one technical challenge remaining to be overcome is the high energy cost of algae harvesting and dewatering that accounts for $20-30 \%$ of the total operating cost [2]. Conventional methods for microalgae dewatering include centrifugation, flocculation, sedimentation and any combination of these. But they are either prohibitively energy intensive, damaging algal cells, or negatively affecting biomass quality [3]. Pressure-driven membrane filtration processes such as ultrafiltration are alternative techniques for microalgae harvesting due to their higher separation efficiency, easy operation and no or little need of chemical addition. Petrusevski et al. [4] reported to harvest microalgae with an overall intact biomass recovery between $70 \%$ and $89 \%$ by using tangential crossflow $0.45 \mu \mathrm{m}$ membrane filtration. However, these pressure-driven membrane processes are highly susceptible to fouling with much of them irreversible [5].

\footnotetext{
* Corresponding author at: School of Engineering, University of Glasgow, Room 803, Rankine Building, Glasgow, Scotland, G12 8LT, United Kingdom.

E-mail address: xue.jin@glasgow.ac.uk (X. Jin).
}

Forward osmosis (FO) membrane filtration process is an emerging and promising alternative for microalgae primary harvesting prior to further thickening and drying. It is a passive process that uses an osmotic pressure difference as the driving force. In the FO process, water moves across a semipermeable membrane from a feed solution of lower osmotic pressure (e.g., algal suspension) to a draw solution of higher osmotic pressure (e.g., desalination brine) [6]. In comparison with pressure-driven microfiltration and ultrafiltration, FO demonstrates unparalleled advantages of lower energy consumption, superior separation efficiency, potentially lower fouling tendency and more recovery of intact algal cells due to the lack of hydraulic pressure [7]. With the development of more efficient membranes, FO has been considered for various dewatering applications, such as pre-concentration of wastewater to facilitate the subsequent anaerobic digestion [8], landfill leachate dewatering [6] and concentration of fruit juice [9].

In 2009, the National Aeronautics and Space Administration (NASA) proposed an elegant concept - a coastal floating system integrating photobioreactor and FO [10]. In brief, the system is designed to grow microalgae in sewage inside a plastic bag that floats offshore. The bag is made of FO membranes that allow fresh water to flow out into the ocean while concentrating the algal biomass. As long as the draw solution has higher osmotic pressure than the algal suspension in the feed side, the process can be carried out indefinitely with no other inputs. 
This technology is still in an early stage of development and significant processes of optimizations are required. Some critical issues remain unsolved. For example, high biomass concentration is expected in the concentrated feed water. This will cause potential fouling problem, which can reduce algae dewatering efficiency and increase the overall operating costs and membrane degradation. Understanding the fundamental mechanisms and consequences of membrane fouling is critical to develop efficient and cost-effective fouling control strategies and, thus, enabling more sustainable application of FO membrane technology for microalgae dewatering.

A variety of draw solutions have been explored for FO applications, such as naturally available ocean water [11], brine from desalination plants [12], thermolytic salt ammonium bicarbonate and various simple electrolytes (e.g., $\mathrm{NaCl}$ and $\mathrm{MgCl}_{2}$ ) [13]. Among these, the use of desalination brine for algae dewatering is very promising because (1) it is usually viewed as an unwanted residue and thus cheap; (2) it contains a significant amount of osmotic energy due to its very high salinity; (3) disposal of large quantities of brine can be very costly and there is an increasing concern over the adverse environmental and ecological impacts of brine disposal. When brine is used to draw clean water out of algae suspension in the FO process, the high quality permeate water mixes with the brine and substantially reduces its concentration. Thus the algae dewatering process also allows cost effective and environmentally friendly brine disposal.

The back diffusion of salts from draw solution to feed solution may induce complicated interactions with algal biomass and thus the draw solution chemistry may play an important role in the FO performance for algae dewatering. Zou et al. [14] highlighted the adverse impact of $\mathrm{Mg}^{2+}$ ions, that bind with carboxylic acid functional groups during the concentration of Chlorella sorokiniana and thus cause a severe flux decline. Given the diversity of draw solutions and complexity of algal biomass, further research efforts are necessary to better understand the FO process applied for algal dewatering. For example, the intricate relationship between draw solution types, algal species, membrane fouling behavior, and algal dewatering efficiency is still poorly understood. In addition, more study is needed to determine the maximum achievable algae concentration level, which depends on membrane type and orientation [15], module configuration and hydrodynamic conditions (e.g., spacer design) [16], and feed/draw solution composition and concentration [17]. These factors influence mass transfer, internal concentration polarization (ICP) and membrane fouling and thus govern the FO performance.

As a first step towards filling these knowledge gaps, we conducted a study of green algae Scenedesmus obliquus dewatering by commercially available FO membranes. S. obliquus was selected as model microalgae because it is often applied for biofuels production and wastewater treatment [18]. The objectives of this study were to (1) systematically investigate the effect of draw solution chemistry on flux behavior and algal dewatering efficiency; and (2) develop a fundamental understanding of the membrane fouling mechanisms involved during algal dewatering process with FO, by combining the data derived from filtration experiments and microalgae suspension/membrane characterization. The effect of orientation, membrane type and feed spacer was also investigated. The findings of this study provide comprehensive insights into the FO process design in terms of draw solution selection, membrane module design and fouling control.

\section{Materials and methods}

\subsection{Microalgae cultivation and characterization}

Freshwater green algae S. obliquus were obtained from Culture Collection of Algae and Protozoa (CCAP, UK). The alga has an ellipsoidal shape and is around $5 \mu \mathrm{m}$ in width and $10 \mu \mathrm{m}$ in length based on microscopic observation (Olympus IX71, Olympus Corporation, Tokyo, Japan). S. obliquus was cultivated in modified BG-11 medium
(Table A.1, Appendix A) following the recommendations of CCAP. Suspensions were continuously stirred and lit with fluorescent lights at $100 \mu \mathrm{mol}$ photons $/ \mathrm{m}^{2} \mathrm{~s}$. Air $(75 \mathrm{~L} / \mathrm{h})$, naturally containing a small portion of $\mathrm{CO}_{2}$, was also sparged into the photobioreactor to maintain optimal algal growth. The $\mathrm{pH}$ of the culture ranged from 6.5 to 7.5 depending on the growth phase. The growth of S. obliquus was periodically monitored by measuring its optical density with a spectrophotometer (Helios Zeta, Thermo Scientific, UK) at $435 \mathrm{~nm}$ wavelength [19]. The microalgae suspension was harvested at the end of exponential phase when its concentration reached $2-3 \mathrm{~g}$ dry weight/L. This stock solution of microalgal biomass was diluted in BG-11 medium for the preparation of the feed solution (containing $0.2 \mathrm{~g} / \mathrm{L}$ algal biomass) used in all FO experiments, to mimic the algae concentration obtained in raceway ponds [20]. In the BG-11 medium, the algal cells exhibited negatively zeta potential of $15.45 \pm 1.87 \mathrm{mV}$ (Zetasizer nano, Malvern Instruments Ltd., UK).

\subsection{Draw solution chemistry}

Draw solution chemistries investigated for $\mathrm{FO}$ experiments included simple electrolytes $\left(\mathrm{NaCl}, \mathrm{MgCl}_{2}\right.$ and $\left.\mathrm{CaCl}_{2}\right)$ and a commercial sea salt. All salts were ACS reagent grade (Sigma-Aldrich, UK). The draw solution was made by dissolving each type of solute to achieve the desired concentrations. The concentration of sea salt was $70 \mathrm{~g} / \mathrm{L}$ to mimic the salinity of brine from typical reverse osmosis (RO) desalination plant [21]. The ionic composition of $70 \mathrm{~g} / \mathrm{L}$ sea salt is provided in Table 1 (calculated from manufacturer's data). The osmotic pressure of feed solution and all draw solutions was determined from

$\pi=\beta C R T$

where $\pi$ is the osmotic pressure (Pa), $\beta$ is the dimensionless Van't Hoff factor, $C$ is the molar concentration of solute, $R$ is the gas constant $\left(8.314 \mathrm{~m}^{3} \cdot \mathrm{Pa} / \mathrm{K} \cdot \mathrm{mol}\right)$ and $T$ is the absolute temperature $(\mathrm{K})$. The feed solution (BG-11 medium) had a much lower osmotic pressure (0.9 bar) than the draw solutions. Thus the FO driving force that causes the movement of water through membrane from algal biomass side to draw solution is dominated by the draw solution composition. In order to conduct a meaningful comparison of filtration performance between different draw solutions, $68.96 \mathrm{~g} / \mathrm{L} \mathrm{NaCl}$ (55.1 bar), $86.55 \mathrm{~g} / \mathrm{L}$ $\mathrm{MgCl}_{2}$ (87.7 bar) and $114.31 \mathrm{~g} / \mathrm{L} \mathrm{CaCl}_{2}$ (80.8 bar) were used to achieve the same initial permeate flux $\left(\sim 7 \mathrm{~L} / \mathrm{m}^{2} \cdot \mathrm{h}\right)$ with $70 \mathrm{~g} / \mathrm{L}(55.3 \mathrm{bar})$ sea salt.

\subsection{FO membranes}

Two commercial FO membranes (CTA and TFC) were used in this study. Both membranes were provided by Hydration Technology Innovations (Albany, OR, USA). CTA has a dense selective layer (active layer) made of cellulose triacetate and TFC has an active layer made of polyamide. Both membranes have asymmetric structure with the active layer supported by embedded polyester screen mesh to enhance their

Table 1

Ion composition of $70 \mathrm{~g} / \mathrm{L}$ sea salt.

\begin{tabular}{lllc}
\hline Major ion & Symbol & Concentration $(\mathrm{g} / \mathrm{L})$ & Mass Ratio $(\%)$ \\
\hline Chloride & $\mathrm{Cl}^{-}$ & 39.55 & 56.50 \\
Sodium & $\mathrm{Na}^{+}$ & 22.10 & 31.57 \\
Sulfate & $\mathrm{SO}_{4}^{2-}$ & 3.40 & 4.86 \\
Magnesium & $\mathrm{Mg}^{2+}$ & 2.71 & 3.87 \\
Potassium & $\mathrm{K}^{+}$ & 0.86 & 1.23 \\
Calcium & $\mathrm{Ca}^{2+}$ & 0.82 & 1.17 \\
Bicarbonate & $\mathrm{HCO}_{3}^{-}$ & 0.41 & 0.59 \\
Bromide & $\mathrm{Br}^{-}$ & 0.155 & 0.16 \\
Strontium & $\mathrm{Sr}^{2+}$ & $1.8 \cdot 10^{-2}$ & 0.03 \\
Boron & $\mathrm{B}(\mathrm{OH})_{3}$ & $1.1 \cdot 10^{-2}$ & 0.02 \\
\hline
\end{tabular}


mechanical strength. Both membrane orientations, active layer facing feed solution (AL-FS) and active layer facing draw solution (AL-DS), were tested.

The pure water permeability $(A)$ and solute permeability $(B)$ of the FO membranes were determined at $25 \pm 1{ }^{\circ} \mathrm{C}$ in a pressurized dead-end filtration test unit (Millipore, UK) with a stirring speed of $6 \times \mathrm{g}$ to minimize external concentration polarization on the membrane surface. The effective membrane area was $40 \mathrm{~cm}^{2}$. The pure water permeability was determined by measuring the permeate water flux over a range of applied pressures (1-5 bar). Using a feed solution containing $10 \mathrm{mM}$ of individual simple electrolyte or commercial sea salt, the rejection of the corresponding solutes was calculated from feed and permeate conductivity measurements (Ultrameter II, Myron L Company, CA, USA). The solute permeability was calculated based on the solution-diffusion theory [22]:

$B=A \cdot(\Delta P-\Delta \pi) \cdot\left(\frac{1}{R_{S}}-1\right)$

where $\Delta P$ and $\Delta \pi$ are the hydraulic pressure difference and osmotic pressure difference across the membrane, respectively; $R_{S}$ is the rejection of specific solutes.

\subsection{FO experimental setup}

All FO experiments were conducted using a custom fabricated bench-scale crossflow FO system (Fig. B.1, Appendix B), which is similar to that described in our previous studies [23-25]. Conceptual illustration of microalgae dewatering by FO is depicted in Fig. B.2 (Appendix B). Briefly, a membrane coupon with an effective area of $200 \mathrm{~cm}^{2}$ was housed in a cross-flow membrane cell. Diamond-patterned spacers were obtained from a commercial FO spiral wound module (HTI, OsMem $^{\mathrm{TM}}$ ) and placed on both sides of the membrane to promote mass transfer [26]. Counter-current flow was used to circulate both feed and draw solutions on both sides of membrane using a variablespeed peristaltic pump (Cole-Parmer, Vernon Hills, IL, USA). The crossflow velocities were maintained at $9.6 \mathrm{~cm} / \mathrm{s}$ during all experiments on both side of the membrane. The feed solution was well mixed by a magnetic stirrer to prevent microalgae sedimentation. The draw solution tank was placed on a digital scale (Denver Instrument, Denver, USA) and weight changes as a function of time were used to determine permeate water flux. The solution temperature was maintained at $25 \pm$ $1{ }^{\circ} \mathrm{C}$ using a recirculating water chiller/heater (Fisher Scientific, Loughborough, UK). Samples from the feed tank and draw solution tank were taken at specified time intervals for conductivity measurement.

\subsection{Protocols of algae dewatering by FO Membrane Filtration}

FO algae dewatering experiments comprised three steps: (1) equilibration, (2) algae dewatering, and (3) cleaning. First, membrane coupon was equilibrated with BG-11 medium as feed solution and desired draw solution for at least 30 min until a stable water flux was achieved. This flux was recorded as initial flux. Second, algae dewatering was initiated with $1 \mathrm{~L}$ of algae suspension $(0.2 \mathrm{~g} / \mathrm{L})$ in feed tank and $6 \mathrm{~L}$ of draw solution. The FO filtrations were considered complete when the concentration factor reached $4(750 \mathrm{~mL}$ of permeate was extracted from the original algal suspension), which took 4.5-6.5 h depending on membrane type, orientation and draw solution composition. To minimize the impact of draw solution dilution on FO performance, draw solution concentration was monitored by conductivity measurement and maintained constant by dosing from a concentrated stock solution [27]. To quantify the permeate flux loss caused by algae fouling, baseline experiments were also conducted under identical conditions to the corresponding algae FO experiments, except no algae biomass was added into the feed solution. The flux loss caused by algae fouling was determined by:

$\Delta J_{w}=1-\frac{J_{w, a}}{J_{w, b}}$

where $\Delta J_{w}$ is normalized water flux loss, $J_{w, a}$ and $J_{w, b}$ are water flux in algae dewatering test and baseline test at specific concentration factor, respectively.

At the end of algae dewatering experiments, both feed and draw solution tanks were emptied and the membrane system was rinsed with deionized water at a crossflow velocity of $19.2 \mathrm{~cm} / \mathrm{s}$ for $30 \mathrm{~min}$. After rinsing, permeate water flux was measured to determine flux recovery (cleaning efficiency). Conditions for this flux test were identical to those for initial water flux test of the virgin membrane (as mentioned above). To further clean the fouled membrane, osmotic backwashing with deionized water as draw solution and salt water as feed solution was performed for $30 \mathrm{~min}$. The permeate flux was then measured again to determine flux recovery with the conditions identical to those for initial water flux test. Flux recover was determined from.

Flux recovery $=\frac{J_{w, c}}{J_{w, 0}}$

where $J_{w, 0}$ and $J_{w, c}$ are initial water flux and water flux after cleaning, respectively.

\subsection{Extracellular proteins and carbohydrates analysis}

At specified time intervals, feed samples $(15 \mathrm{ml})$ were taken and centrifuged at $6 \times \mathrm{g}$ for $20 \mathrm{~min}$. Protein concentration in the supernatant was determined using the modified Lowry method with bovine serum albumin as a standard [28]. Carbohydrate concentration was determined using phenol-sulphuric acid method with glucose as a standard [29]. Total extracellular protein/carbohydrate contents (mg) in the feed solution were then calculated from the product of protein/carbohydrate concentrations $(\mathrm{mg} / \mathrm{L})$ and feed volume at the time when the samples were taken.

\section{Results and discussion}

\subsection{Membranes performance parameters}

Table 2 shows the pure water permeability $(A)$, solute permeability $(B)$, and selectivity $(B / A)$ of the FO membranes used. The $A$ value of CTA membrane was about half that of the TFC membrane. This is consistent with the finding by Ren and McCutcheon [30]. The lower $B / A$ ratios of CTA membrane indicate its better salt rejection compared to TFC membrane. For both membranes, the $B$ values followed the same order of decline: $\mathrm{NaCl}>$ sea salts $>\mathrm{MgCl}_{2}>\mathrm{CaCl}_{2}$. The higher $B$ value of $\mathrm{NaCl}$ is attributed to the smaller hydrated radius and lower electrical charge of $\mathrm{Na}^{+}$compared to $\mathrm{Mg}^{2+}$ and $\mathrm{Ca}^{2+}[31,32]$.

\subsection{Flux decline during dewatering of S. obliquus by FO membranes}

This section shows the water flux behavior during the filtration of S. obliquus with sea salts as draw solution. The filtration flux as a function of volumetric concentration factor for both baseline and algae dewatering experiments are summarized in Fig. 1a. In all cases, water flux declined with the increase of concentration factor. The flux decline is attributed to (1) membrane fouling and (2) a loss of osmotic driving force across the FO membrane due to an enhanced salinity in the feed solution (Fig. 1c). To better understand membrane fouling during algae dewatering, it is necessary to separate the effect from feed salinity increment. In this regards, the baseline flux was discussed first.

For both CTA and TFC membranes, the initial baseline flux in the ALFS orientation was lower than that in the AL-DS orientation. This 
Table 2

Membrane performance parameters.

\begin{tabular}{|c|c|c|c|c|c|c|c|c|c|}
\hline \multirow[t]{2}{*}{ Membrane } & \multirow{2}{*}{$\frac{\text { Water permeability }(\mathrm{m} / \mathrm{s} \mathrm{Pa})}{\mathrm{A}}$} & \multicolumn{4}{|c|}{ Solute permeability (m/s) } & \multicolumn{4}{|c|}{ Selectivity (KPa) } \\
\hline & & $B_{\text {sea salts }}$ & $\mathrm{B}_{\mathrm{NaCl}}$ & $\mathrm{B}_{\mathrm{MgCl} 2}$ & $\mathrm{~B}_{\mathrm{CaCl} 2}$ & $B_{\text {sea salts } /} A$ & $\mathrm{~B}_{\mathrm{NaCl}} / \mathrm{A}$ & $\mathrm{B}_{\mathrm{MgCl} 2} / \mathrm{A}$ & $\mathrm{B}_{\mathrm{CaCl} 2} / \mathrm{A}$ \\
\hline CTA & $1.51 \times 10^{-12}$ & $5.08 \times 10^{-8}$ & $9.07 \times 10^{-8}$ & $4.69 \times 10^{-8}$ & $3.57 \times 10^{-8}$ & 34 & 60 & 31 & 24 \\
\hline TFC & $2.78 \times 10^{-12}$ & $1.54 \times 10^{-7}$ & $4.34 \times 10^{-7}$ & $1.18 \times 10^{-7}$ & $0.98 \times 10^{-7}$ & 55 & 156 & 42 & 35 \\
\hline
\end{tabular}

observation is consistent with previous studies and is due to the fact that the dilutive ICP in the AL-FS orientation has greater effect on water flux compared to the concentrative ICP effect in the AL-DS orientation $[15,22,26]$. In all the baseline tests, water flux declined with the
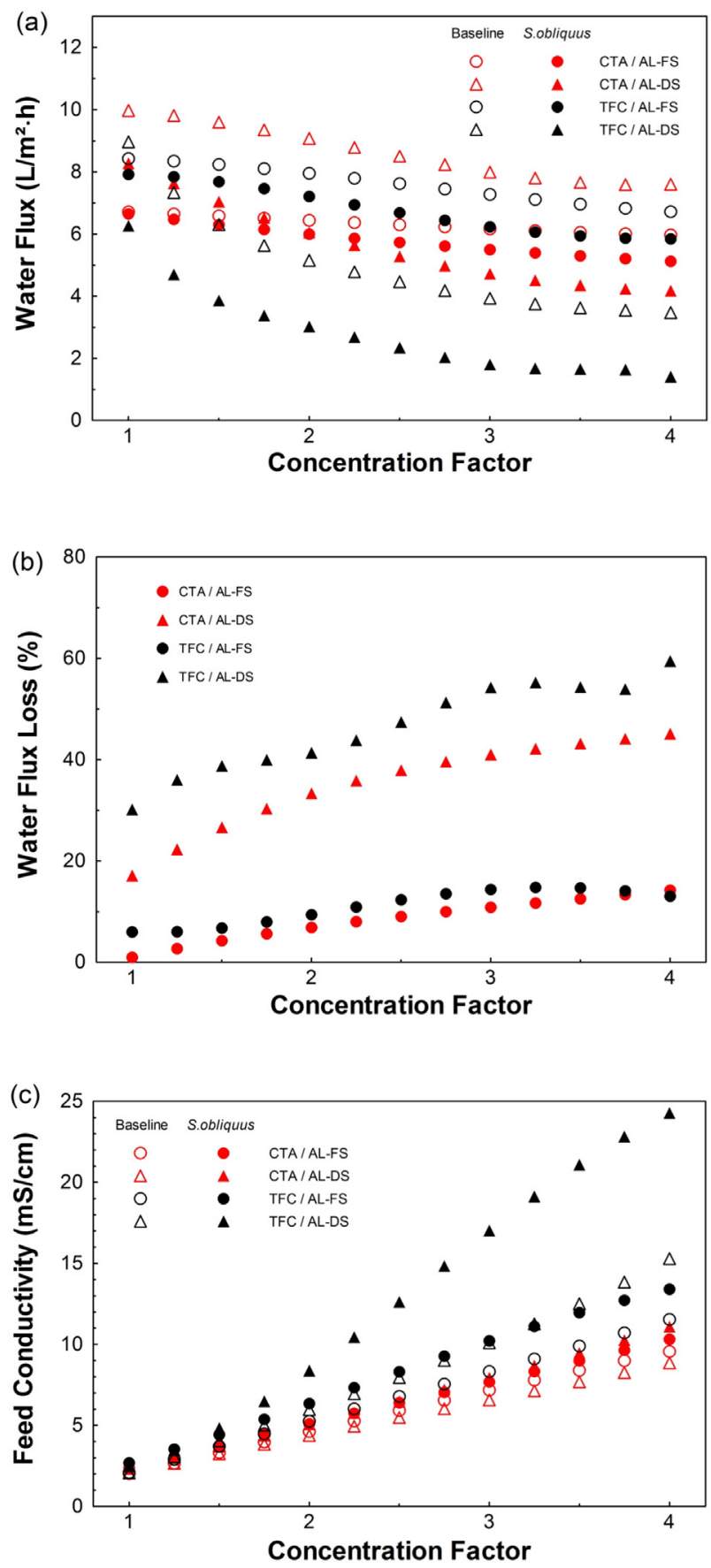

Fig. 1. Changes of water flux and feed conductivity as a function of volumetric concentration factor for CTA and TFC membranes: (a) water flux in baseline and algae dewatering experiments; (b) normalized flux loss; and (c) conductivity in the feed solution. The draw solution contained $70 \mathrm{~g} / \mathrm{L}$ sea salt. increase of concentration factor. This decline can be explained as follows. The extraction of pure water from feed to draw solution and the reverse diffusion of draw solutes into the feed solution led to an enhanced feed conductivity/salinity (Fig. 1c) and thus a reduced osmotic driving force across the membrane active layer. As the water flux (Fig. 1a) and feed conductivity (Fig. 1c) are plotted as a function of concentration factor, greater rate of flux decline and conductivity increment indicate a more severe effect of draw solutes reverse diffusion.

When active layer was facing the feed solution, the TFC membrane achieved a higher initial water flux $\left(8.42 \mathrm{~L} / \mathrm{m}^{2} \cdot \mathrm{h}\right)$ than CTA membrane $\left(6.71 \mathrm{~L} / \mathrm{m}^{2} \cdot \mathrm{h}\right)$. The higher initial flux of TFC membrane is consistent with its higher $A$ value (Table 2). However, the TFC membrane exhibited a more noticeable water flux decline. At the end of baseline tests, TFC membrane showed a greater flux reduction (20.3\%) than CTA membrane (11\%). The greater flux decline of TFC is due to its lower salt rejection (indicated by a higher $B / A$ value in Table 2 ) which led to more back diffusion of draw solutes (Fig. 1c) and thus more reduction in osmotic driving force. In the AL-DS orientation, TFC exhibited a lower initial flux $\left(8.97 \mathrm{~L} / \mathrm{m}^{2} \cdot \mathrm{h}\right)$ than CTA membrane $\left(9.98 \mathrm{~L} / \mathrm{m}^{2} \cdot \mathrm{h}\right)$. Considering its higher $A$ value, this phenomenon indicates that an immediate back diffusion of draw solutes took place during the equilibration step. Draw solutes diffused through the membrane active layer accumulate in the porous support layer to exacerbate ICP effect which caused a reduction in the effective osmotic driving force and thus a lower water flux. At the end of baseline tests, TFC membrane exhibited a much greater flux reduction (61.3\%) compared to CTA membrane (23.8\%). As discussed above, this can be explained by its more severe draw solutes back diffusion (Fig. 1c). For both membranes, flux decline rate was more significant in the AL-DS orientation (particularly for TFC membrane), indicating that the effect of draw solute back diffusion on water flux reduction is more severe (due to the reverse solute diffusion induced ICP) when active layer is facing the draw solution.

The degree of membrane fouling was assessed by comparing the water flux of algae dewatering experiments to its corresponding baseline flux. Fig. 1b presents the normalized flux loss due to algae fouling. Generally, flux loss in the AL-DS orientation increased more drastically with the increase of concentration factor than that in the other orientation. This demonstrates that more severe algae fouling occurred when active layer was facing the draw solution. In the AL-DS orientation, the flux loss increased instantaneously after algae was added into the feed solution, and then slowed down. At the end of tests, the water flux was significantly declined by $59.5 \%$ for TFC membrane and $45.1 \%$ for CTA membrane. Such severe membrane fouling can be caused by a combination of (1) internal adsorption of algal biomass inside the porous support layer of membrane which results in an increase of hydraulic resistance; and (2) pore clogging enhanced concentrative ICP due to the reduction of mass transfer coefficient in the membrane support layer $[22,24]$. In contrast, the AL-FS orientation exhibited a superior fouling resistance. At the end of test, water flux loss was less than $15 \%$ for both membranes. The marginal membrane fouling is attributed to the deposition of algal biomass onto the active layer surface which can change the effective pore size of the membrane through sealing the molecular-scale defects and introducing an additional barrier to restrict the transport of water molecules [24].

Membrane cleaning experiments were performed immediately after algae dewatering in order to test the fouling reversibility. Fig. 2 presents the flux recovery after cleaning with deionized water flushing and by osmotic backwash. In the AL-FS orientation, water flux could be recovered up to $90 \%$ of the initial flux by deionized water flushing and could be further recovered by osmotic backwashing. This suggests that 


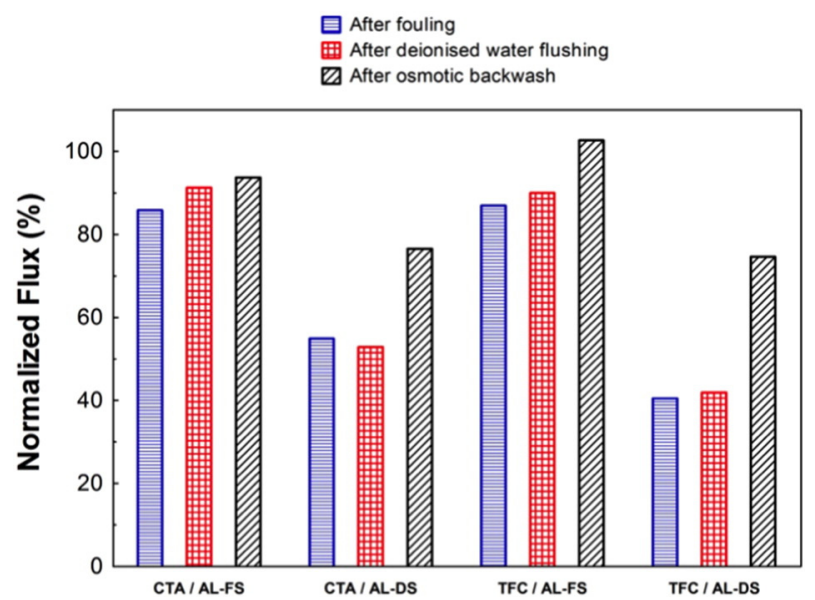

Fig. 2. Flux recovery after cleaning. Note that the flux after fouling is normalized by the flux at the end of baseline test, while the recovered flux after cleaning is normalized by the pure water flux of a clean membrane. Results are presented in percentages.

algal biomass is loosely attached onto membrane surface. Most of the membrane fouling is reversible by simple hydrodynamic cleaning steps. In this regard, algal dewatering by FO may offer a great benefit in eliminating the need for harsh chemical cleaning and air scouring, both of which are widely used for microfiltration and ultrafiltration fouling control but increase membrane degradation, energy consumption, and operating cost. Thus, FO has the promise for low-chemical and energy efficient microalgae dewatering. In the AL-DS orientation, the flux loss could not be recovered by deionized water flushing. The osmotic backwash was not very effective, with flux recovery of only $76 \%$ and $72 \%$ for CTA and TFC membrane, respectively. This observation indicates that algal biomass binds strongly to the internal structure of membrane support layer and this internal adsorption/clogging is the dominating fouling mechanism. Based on the above discussion, AL-FS outperformed AL-DS in the application of algae dewatering.

To better understand the FO performance on algae dewatering and gain more insight into the adverse role of draw solutes back diffusion, the effect of draw solution chemistry on flux behavior and algal dewatering efficiency using CTA membrane in the AL-FS orientation was systematically investigated in next section. The selection of CTA membrane is due to its superior separation efficiency.

\subsection{Effect of draw solution type on algae dewatering}

Fig. 3a presents the water flux loss due to membrane fouling with different types of draw solution. Algae biomass did not cause much membrane fouling for $\mathrm{NaCl}$ and $\mathrm{MgCl}_{2}$ draw solutions during the whole filtration process (water flux loss was below $8 \%$ ). However, when $\mathrm{Ca}^{2+}$ ions were present in the draw solution, flux declined to a greater extent. At the end of experiments, the overall extent of flux loss followed the order of $\mathrm{CaCl}_{2}$ " sea salts (containing $0.82 \mathrm{~g} / \mathrm{L}$ of $\left.\mathrm{Ca}^{2+}\right)>\mathrm{NaCl} \approx \mathrm{MgCl}_{2}$. This finding indicates severe fouling will occur when $\mathrm{CaCl}_{2}$ is used as draw solution although CTA membrane was proven to have a better fouling resistance in the AL-FS orientation [33]. Thus, selection of a proper draw solution should be an important consideration for the FO application in algae dewatering.

Fig. 3b shows the algal biomass concentration in feed tank over the filtration process. The black dash line demonstrates the expected algae concentration as a function of concentration factor, which should reach $0.8 \mathrm{~g} / \mathrm{L}$ at the end of experiments if all the algae biomass can be harvested effectively. However, experimental results were always lower than the prediction. Because feed water was re-circulated back to the feed tank throughout the filtration test, the observed biomass loss is most probably attributed to algae deposition onto membrane and/or feed spacer. A greater loss indicates a more severe deposition. The overall algae harvesting efficiency followed the order of sea
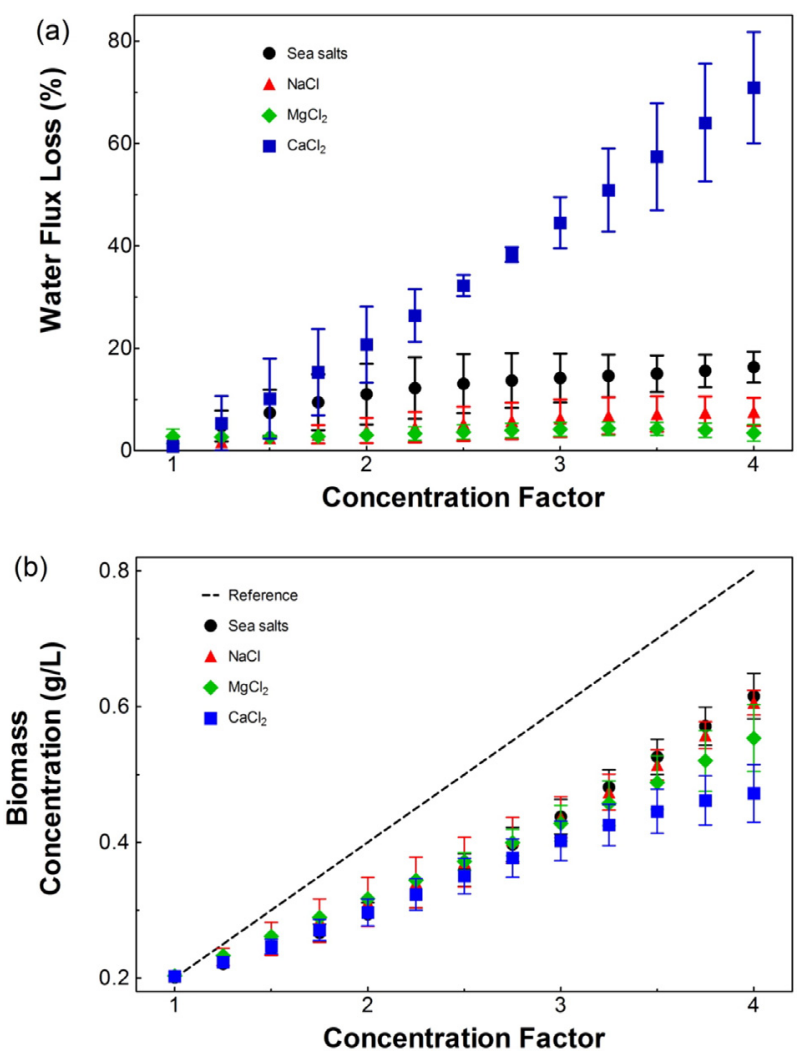

Fig. 3. Influence of draw solution type on (a) water flux loss and (b) algal biomass concentration in the feed tank during S. obliquus dewatering by CTA membrane in the AL-FS orientation. Error bars represent the standard deviations of the average values determined from two independent experiments.

salts $\approx \mathrm{NaCl}>\mathrm{MgCl}_{2}>\mathrm{CaCl}_{2}$. When $\mathrm{CaCl}_{2}$ was used as draw solution, the greatest loss in both water flux (70.9\%) and algal biomass (47.2\%) can be explained by the back diffusion of $\mathrm{Ca}^{2+}$ ions from draw solution into feed solution. The lowest $B$ value for $\mathrm{CaCl}_{2}$ (Table 2 ) indicates there are specific interactions between $\mathrm{Ca}^{2+}$ and algal biomass. Once diffused through the membrane, $\mathrm{Ca}^{2+}$ ions bind preferentially to oxygen atoms of carboxylate groups in a highly organized manner and form bridges between adjacent algal cells as well as their extracellular polysaccharides (EPSs) and soluble microbial products (SMPs), leading to the egg-box-shaped gel network [14,34-36]. As a result, large microalgae flocs were formed in the feed tank (Fig. 4c) which could readily adsorb onto membrane and/or feed spacer. The larger size of microalgae flocs may increase the compressibility of the fouling layers, leading to a greater overall hydraulic resistance [37]. Therefore, the use of $\mathrm{CaCl}_{2}$ as draw solution led to a severe loss in both algal biomass and water flux. When $\mathrm{NaCl}$ and $\mathrm{MgCl}_{2}$ were used as draw solution, no obvious water flux decline $(<8 \%)$ was noticed. However, more than $25 \%$ of algal biomass was lost at the end of experiment. This phenomenon suggests (1) most of the algae deposition takes place onto the mesh spacer in the feed channel rather than onto membrane and (2) the biomass deposited on feed spacer may not augment the hydraulic resistance significantly. The finding in this study disagrees with a previous work by Zou et al. [14]. They showed a significant flux decline during C. sorokiniana dewatering with $\mathrm{MgCl}_{2}$ as draw solution. These conflicting findings can be attributed to the different surface chemistry (such as charge, functional groups and free energy) between $S$. obliquus and $C$. sorokiniana used in the two studies. S. obliquus differs from C. sorokiniana in their cell wall chemical composition by the presence of a great concentration of mannose and fructose, which can bind/interact specifically with $\mathrm{Ca}^{2+}[38,39]$. Clearly, an optimal dewatering method depends on the species of microalgae. As presented in Table 1, sea salt contained $0.8 \mathrm{~g} / \mathrm{L}$ of $\mathrm{Ca}^{2+}$ and $18 \mathrm{mg} / \mathrm{L}$ of $\mathrm{Sr}^{2+}$. The back diffusion 

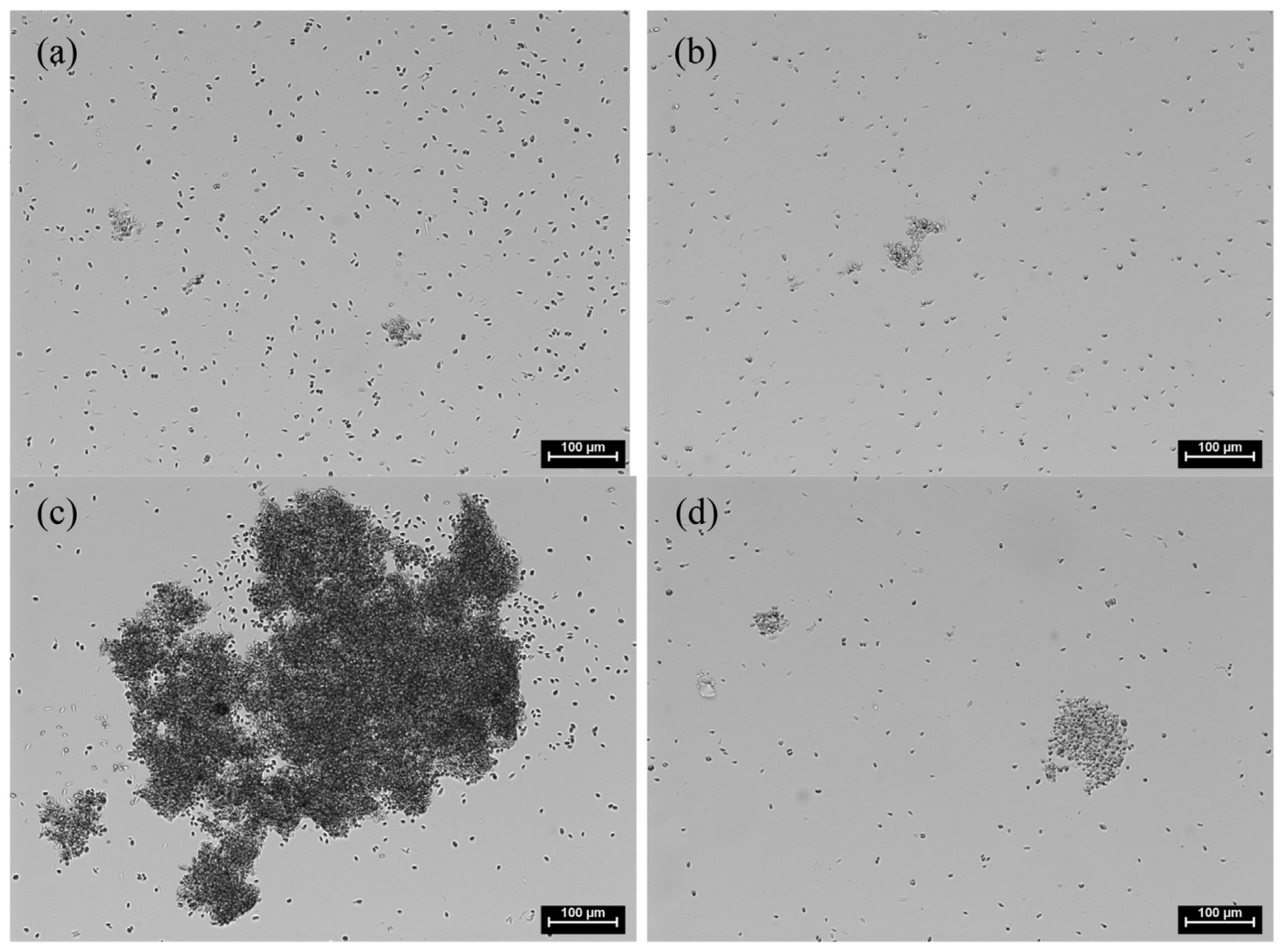

Fig. 4. Microscope image of feed solution after algal dewatering test with different draw solutions: (a) $\mathrm{NaCl} ;\left(\right.$ b) $\mathrm{MgCl}_{2} ;$ (c) $\mathrm{CaCl}_{2}$; and (d) sea salt.

of these divalent cations led to the formation of algal flocs which could readily deposit onto membrane and feed spacer, resulting in $23.1 \%$ of algal biomass lost from the feed and $16.3 \%$ of water flux reduction when sea salt was used as draw solution. The higher flux loss with sea salt as draw solution compared to that with $\mathrm{NaCl}$ and $\mathrm{MgCl}_{2}$ is due to the strong gel formation ability of $\mathrm{Ca}^{2+}\left(\right.$ and $\left.\mathrm{Sr}^{2+}\right)$, which promotes membrane fouling [40]. As confirmed via microscopic observation (Fig. 4), the size of algal flocs formed at the end of FO test followed the order: $\mathrm{CaCl}_{2}$ " sea salt $>\mathrm{MgCl}_{2} \approx \mathrm{NaCl}$.

To further understand the mechanisms underneath the significant fouling with $\mathrm{CaCl}_{2}$ as draw solution, the amount of extracellular carbohydrates and proteins was determined in the feed solution (Fig. 5). In all cases, protein level (below $3 \mathrm{mg}$ ) was more than two orders of magnitude lower than carbohydrate level. Furthermore, no obvious patterns of change were seen in the protein amount. Hence, the discussion below will focus on the changes in carbohydrate amount throughout the algae dewatering experiments. When $\mathrm{NaCl}$ and $\mathrm{MgCl}_{2}$ were used as draw solution, carbohydrates amount showed a decline after FO filtration, followed by an increase to its initial level after deionized water flushing (Fig. 5a). This trend indicates that the extracellular carbohydrates deposit onto membrane and/or feed spacer during the FO processes and the deposited compounds can be easily removed by simple flushing. In contrast, more carbohydrates were detected after filtration with $\mathrm{Ca}^{2+}$-containing draw solutions. Particularly, the carbohydrates amount was up to 3 times higher than its initial value after filtration with $\mathrm{CaCl}_{2}$ as draw solution. The authors speculate that algal cells "leak" more carbohydrates after interacting with the $\mathrm{Ca}^{2+}$ ions back diffused from the draw solution. Indeed, a high local concentration of $\mathrm{Ca}^{2+}$ could cause disturbance in a complex mechanism involved in photosynthesis known as " $\mathrm{Ca}^{2+}$ signal", which is also a response to stress conditions in the nutrition process [41,42]. These carbohydrates, in turn, specifically bind with $\mathrm{Ca}^{2+}$ ions and further enhance the formation of gel network containing algal cells, $\mathrm{Ca}^{2+}$ ions, EPS and SMP $[22,33,43]$. Further investigation needs to support this hypothesis.
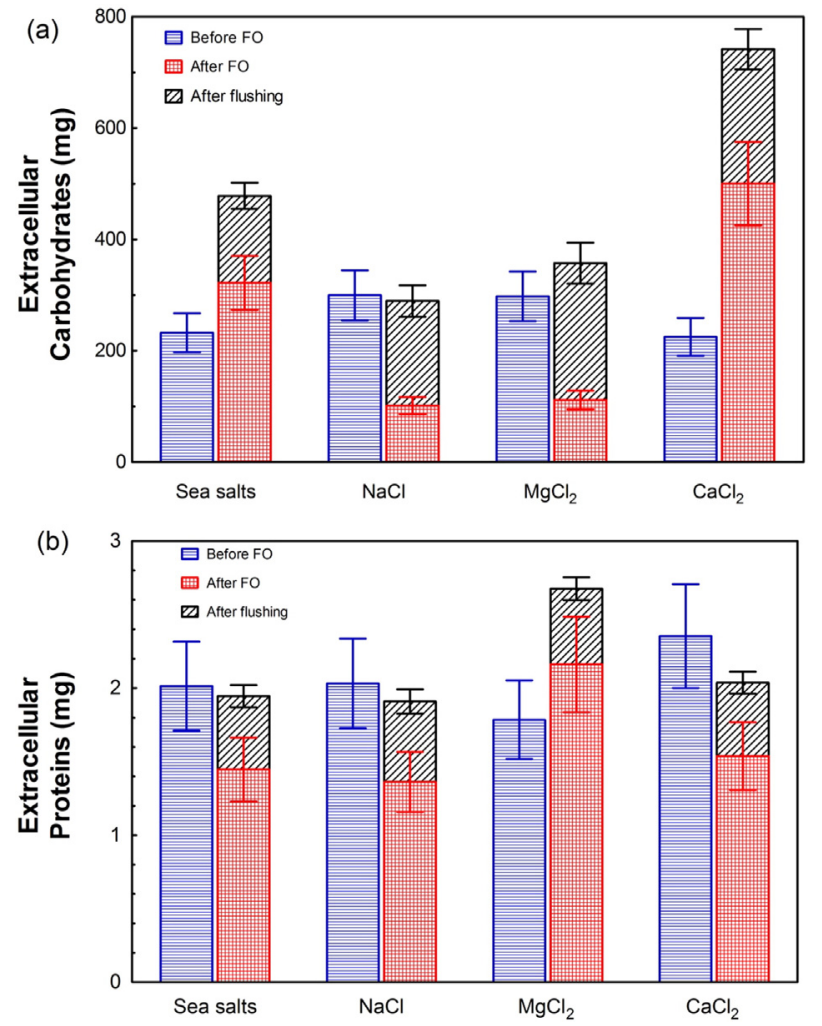

Fig. 5. Extracellular (a) carbohydrate and (b) protein content in feed solution. 


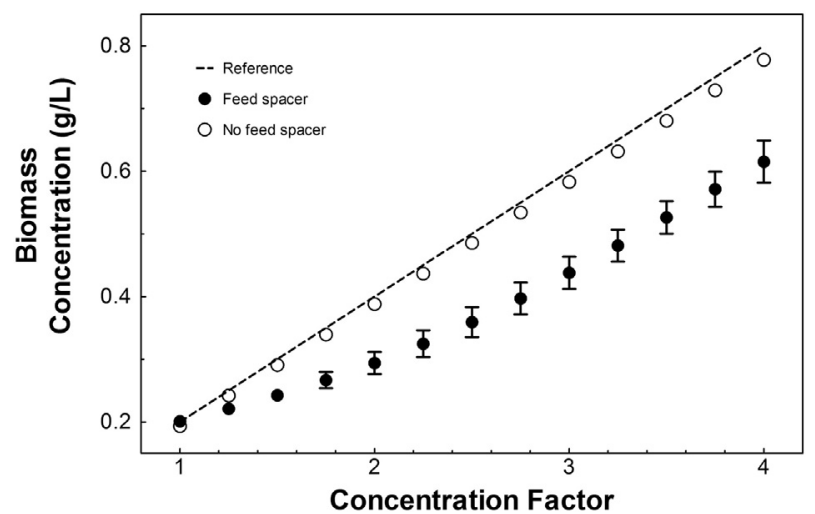

Fig. 6. Effect of feed channel spacer on algal biomass concentration in the feed tank during S. obliquus dewatering by CTA membrane in the AL-FS orientation. The draw solution contained $70 \mathrm{~g} / \mathrm{L}$ sea salt.

\subsection{Effect of feed spacer on algae dewatering}

To test our hypothesis that most algal biomass deposits onto and/or traps inside the feed spacer, FO experiments with sea salt as draw solution were performed without a spacer in the feed channel. Fig. 6 shows the effect of feed spacer on algal biomass concentration. Without using a feed spacer, the experimentally measured biomass concentration was very close to the predicated values. At the end of test, over $95 \%$ of the algal biomass was harvested in the feed tank, significantly higher than that achieved with a feed spacer (around 75\%). These findings revealed a negative effect of using feed spacer on algae dewatering efficacy due to the easy accumulation of algal cells inside spacer. However, the beneficial effect of feed spacer is well known for both pressure-driven and osmotically driven membrane filtration thanks to the improved mass transfer (and thus the reduced external concentration polarization effect) over the membrane surface [44]. Hence, in the application FO for algae dewatering, feed spacer needs to be further optimized in terms of material and geometry to reduce the risk of cell accumulation into the spacer and enhance mass transfer over the membrane surface in the feed channel.

\section{Conclusions}

This study explored the potential of utilizing FO as a low-energy and low-chemical consuming process for microalgae dewatering. Effects of membrane orientation, draw solution chemistry and feed spacer were investigated. AL-FS orientation outperformed AL-DS orientation due to its much lower membrane fouling and greater cleaning efficiency. Algae dewatering by FO in the AL-FS orientation may eliminate the need for harsh chemical cleaning which not only shortens membrane life but also increases operating cost. When using RO desalination brine as draw solution, the diluted brine offers additional benefits including reduced environmental impact of brine discharge together with reduced energy consumption/cost in RO desalination. In the AL-FS orientation, the efficiency and productivity of the dewatering process depended on draw solution chemistry. Among the four types of draw solution tested, $\mathrm{NaCl}$ exhibited the best results. In contrast, for $\mathrm{Ca}^{2+}$-containing draw solutions, back diffusion of $\mathrm{Ca}^{2+}$ ions into the feed solution encouraged S. obliquus to excrete more carbohydrates, accelerated the formation of algal flocs, enhanced the rate and extent of flux decline and reduced the algae dewatering efficiency. In addition, a large amount of microalgae adhered onto feed spacer which negatively affects the whole process yield. Further, studies on feed spacer optimization and FO dewatering of other algae species are necessary.

\section{Acknowledgments}

This work was supported by the School of Engineering, University of Glasgow. The first author was supported by James Watt Scholarships. These financial supports are gratefully acknowledged.

\section{Appendix A. Supplementary data}

Supplementary data to this article can be found online at http://dx. doi.org/10.1016/j.algal.2016.01.014.

\section{References}

[1] S.A. Razzak, M.M. Hossain, R.A. Lucky, A.S. Bassi, H. de Lasa, Integrated $\mathrm{CO}_{2}$ capture, wastewater treatment and biofuel production by microalgae culturing-a review, Renew. Sust. Energ. Rev. 27 (2013) 622-653.

[2] C. Gudin, C. Thepenier, Bioconversion of solar energy into organic chemicals by microalgae, Adv. Biotechnol. Process. 6 (1986) 73-110.

[3] C.-Y. Chen, K.-L. Yeh, R. Aisyah, D.-J. Lee, J.-S. Chang, Cultivation, photobioreactor design and harvesting of microalgae for biodiesel production: a critical review, Bioresour. Technol. 102 (2011) 71-81.

[4] B. Petruševski, G. Bolier, A.N. Van Breemen, G.J. Alaerts, Tangential flow filtration: a method to concentrate freshwater algae, Water Res. 29 (1995) 1419-1424.

[5] M. Rickman, J. Pellegrino, R. Davis, Fouling phenomena during membrane filtration of microalgae, J. Membr. Sci. 423-424 (2012) 33-42.

[6] T.Y. Cath, A.E. Childress, M. Elimelech, Forward osmosis: principles, applications, and recent developments, J. Membr. Sci. 281 (2006) 70-87.

[7] M.R. Bilad, H.A. Arafat, I.F.J. Vankelecom, Membrane technology in microalgae cultivation and harvesting: a review, Biotechnol. Adv. 32 (2014) 1283-1300.

[8] X. Zhang, Z. Ning, D.K. Wang, J.C. Diniz da Costa, Processing municipal wastewaters by forward osmosis using CTA membrane, J. Membr. Sci. 468 (2014) 269-275.

[9] K.B. Petrotos, H.N. Lazarides, Osmotic concentration of liquid foods, J. Food Eng. 49 (2001) 201-206

[10] R.D. Marlaire, NASA envisions "clean energy" from algae grown in waste water, http://www.nasa.gov/centers/ames/news/features/2009/clean_energy_042209. html2009.

[11] N.C. Nguyen, S.-S. Chen, H.-Y. Yang, N.T. Hau, Application of forward osmosis on dewatering of high nutrient sludge, Bioresour. Technol. 132 (2013) 224-229.

[12] C. Lundin, C.S.o.M.D.o.E. Science, Engineering, A Novel Hybrid Forward Osmosis Process for Drinking Water Augmentation Using Impaired Water and Saline Water Sources, Colorado School of Mines, 2008.

[13] A. Achilli, T.Y. Cath, A.E. Childress, Selection of inorganic-based draw solutions for forward osmosis applications, J. Membr. Sci. 364 (2010) 233-241.

[14] S. Zou, Y. Gu, D. Xiao, C.Y. Tang, The role of physical and chemical parameters on forward osmosis membrane fouling during algae separation, J. Membr. Sci. 366 (2011) 356-362.

[15] G.T. Gray, J.R. McCutcheon, M. Elimelech, Internal concentration polarization in forward osmosis: role of membrane orientation, Desalination 197 (2006) 1-8.

[16] S.R. Suwarno, X. Chen, T.H. Chong, V.L. Puspitasari, D. McDougald, Y. Cohen, S.A. Rice, A.G. Fane, The impact of flux and spacers on biofilm development on reverse osmosis membranes, J. Membr. Sci. 405-406 (2012) 219-232.

[17] Q. Ge, M. Ling, T.-S. Chung, Draw solutions for forward osmosis processes: developments, challenges, and prospects for the future, J. Membr. Sci. 442 (2013) 225-237.

[18] G. Hodaifa, S. Sánchez, M.E. Martínez, R. Órpez, Biomass production of Scenedesmus obliquus from mixtures of urban and olive-oil mill wastewaters used as culture medium, Appl. Energy 104 (2013) 345-352.

[19] A.A., Lúcia Helena Ribeiro Rodrigues, Maria Teresa Raya-Rodriguez, Nelson Ferreira Fontoura, Algal density assessed by spectrophotometry: a calibration curve for the unicellular algae Pseudokirchneriella subcapitata, J. Environ. Chem. Ecotoxicol. 3.8 (2011) 225-228.

[20] Y. Chisti, Biodiesel from microalgae, Biotechnol. Adv. 25 (2007) 294-306.

[21] J.M. Arnal, M. Sancho, I. Iborra, J.M. Gozálvez, A. Santafé, J. Lora, Concentration of brines from RO desalination plants by natural evaporation, Desalination 182 (2005) 435-439.

[22] C.Y. Tang, Q. She, W.C.L. Lay, R. Wang, A.G. Fane, Coupled effects of internal concentration polarization and fouling on flux behavior of forward osmosis membranes during humic acid filtration, J. Membr. Sci. 354 (2010) 123-133.

[23] X. Jin, C.Y. Tang, Y. Gu, Q. She, S. Qi, Boric acid permeation in forward osmosis membrane processes: modeling, experiments, and implications, Environ. Sci. Technol. 45 (2011) 2323-2330.

[24] X. Jin, Q. She, X. Ang, C.Y. Tang, Removal of boron and arsenic by forward osmosis membrane: influence of membrane orientation and organic fouling, J. Membr. Sci. 389 (2012) 182-187.

[25] X. Jin, J. Shan, C. Wang, J. Wei, C.Y. Tang, Rejection of pharmaceuticals by forward osmosis membranes, J. Hazard. Mater. 227-228 (2012) 55-61.

[26] J.R. McCutcheon, M. Elimelech, Influence of concentrative and dilutive internal concentration polarization on flux behavior in forward osmosis, J. Membr. Sci. 284 (2006) 237-247

[27] B.D. Coday, D.M. Heil, P. Xu, T.Y. Cath, Effects of transmembrane hydraulic pressure on performance of forward osmosis membranes, Environ. Sci. Technol. 47 (2013) $2386-2393$. 
[28] A. Bensadoun, D. Weinstein, Assay of proteins in the presence of interfering materials, Anal. Biochem. 70 (1976) 241-250.

[29] M. DuBois, K.A. Gilles, J.K. Hamilton, P.A. Rebers, F. Smith, Colorimetric method for determination of sugars and related substances, Anal. Chem. 28 (1956) 350-356.

[30] J. Ren, J.R. McCutcheon, A new commercial thin film composite membrane for forward osmosis, Desalination 343 (2014) 187-193.

[31] E.R. Nightingale, Phenomenological theory of ion solvation. Effective radii of hydrated ions, J. Phys. Chem. 63 (1959) 1381-1387.

[32] J. Schaep, B. Van der Bruggen, C. Vandecasteele, D. Wilms, Influence of ion size and charge in nanofiltration, Sep. Purif. Technol. 14 (1998) 155-162.

[33] Y. Gu, Y.-N. Wang, J. Wei, C.Y. Tang, Organic fouling of thin-film composite polyamide and cellulose triacetate forward osmosis membranes by oppositely charged macromolecules, Water Res. 47 (2013) 1867-1874.

[34] D.-W. Gao, T. Zhang, C.-Y.Y. Tang, W.-M. Wu, C.-Y. Wong, Y.H. Lee, D.H. Yeh, C.S. Criddle, Membrane fouling in an anaerobic membrane bioreactor: differences in relative abundance of bacterial species in the membrane foulant layer and in suspension, J. Membr. Sci. 364 (2010) 331-338.

[35] T.A. Davis, F. Llanes, B. Volesky, A. Mucci, Metal selectivity of Sargassum spp. and their alginates in relation to their $\alpha$-l-guluronic acid content and conformation, Environ. Sci. Technol. 37 (2002) 261-267.

[36] X. Jin, X. Huang, E.M.V. Hoek, Role of specific ion interactions in seawater RO Membrane fouling by alginic acid, Environ. Sci. Technol. 43 (2009) 3580-3587.
[37] X. Jin, A. Jawor, S. Kim, E.M.V. Hoek, Effects of feed water temperature on separation performance and organic fouling of brackish water RO membranes, Desalination 239 (2009) 346-359.

[38] H. Takeda, Taxonomical assignment of chlorococal algae from their cell wall composition, Int. J. Plant Biochem. 34 (1993) 1053-1055

[39] H.-A. Tajmir-Riahi, Sugar interaction with calcium ion. Synthesis and vibrational spectra of crystalline $\beta$-d-fructose and its calcium halide adducts, J. Inorg. Biochem. 27 (1986) 123-131.

[40] Y. Fang, S. Al-Assaf, G.O. Phillips, K. Nishinari, T. Funami, P.A. Williams, Binding behavior of calcium to polyuronates: comparison of pectin with alginate, Carbohydr. Polym. 72 (2008) 334-341.

[41] F. Rolland, B. Moore, J. Sheen, Sugar sensing and signaling in plants, Plant Cell 14 (2002) 185-205.

[42] A.M. Hetherington, C. Brownlee, The generation $\mathrm{Of} \mathrm{Ca}^{2+}$ signals in plants, Annu. Rev Plant Biol. 55 (2004) 401-427.

[43] B. Mi, M. Elimelech, Chemical and physical aspects of organic fouling of forward osmosis membranes, J. Membr. Sci. 320 (2008) 292-302.

[44] S. Zou, Y.-N. Wang, F. Wicaksana, T. Aung, P.C.Y. Wong, A.G. Fane, C.Y. Tang, Direct microscopic observation of forward osmosis membrane fouling by microalgae: critical flux and the role of operational conditions, J. Membr. Sci. 436 (2013) 174-185. 